\title{
How to adapt the pulmonary rehabilitation programme to patients with chronic respiratory disease other than COPD
}

\author{
Anne E. Holland ${ }^{1,2,3}$, Karin Wadell ${ }^{4}$ and Martijn A. Spruit ${ }^{5}$ \\ Number 3 in the Series "Thematic Review Series on Pulmonary Rehabilitation" \\ Edited by M.A. Spruit and E.M. Clini

\begin{abstract}
Affiliations: ${ }^{1}$ Dept of Physiotherapy, La Trobe University, Melbourne, ${ }^{2}$ Dept of Physiotherapy, Alfred Health, Melbourne, and ${ }^{3}$ Institute for Breathing and Sleep, Melbourne, Australia. ${ }^{4}$ Dept of Community Medicine and Rehabilitation, Physiotherapy, Umeå University, Umeå, Sweden. ${ }^{5}$ Program Development Center, Center of Expertise for Chronic Organ Failure, CIRO+, Horn, The Netherlands.
\end{abstract}

Correspondence: A.E. Holland, Dept of Physiotherapy, La Trobe University Clinical School, Alfred Health, 99 Commercial Rd, Melbourne 3004, Australia. E-mail: a.hollanddalfred.org.au

ABSTRACT Dyspnoea, fatigue, reduced exercise tolerance, peripheral muscle dysfunction and mood disorders are common features of many chronic respiratory disorders. Pulmonary rehabilitation successfully treats these manifestations in chronic obstructive pulmonary disease (COPD) and emerging evidence suggests that these benefits could be extended to other chronic respiratory conditions, although adaptations to the standard programme format may be required. Whilst the benefits of exercise training are well established in asthma, pulmonary rehabilitation can also provide evidence-based interventions including breathing techniques and self-management training. In interstitial lung disease, a small number of trials show improved exercise capacity, symptoms and quality of life following pulmonary rehabilitation, which is a positive development for patients who may have few treatment options. In pulmonary arterial hypertension, exercise training is safe and effective if patients are stable on medical therapy and close supervision is provided. Pulmonary rehabilitation for bronchiectasis, including exercise training and airway clearance techniques, improves exercise capacity and quality of life. In nonsmall cell lung cancer, a comprehensive interdisciplinary approach is required to ensure the success of pulmonary rehabilitation following surgery. Pulmonary rehabilitation programmes provide important and underutilised opportunities to improve the integrated care of people with chronic respiratory disorders other than COPD.

@ERSpublications

The benefits of pulmonary rehabilitation can be extended to people with a broad range of chronic respiratory conditions http://ow.ly/pnrxB

\section{Introduction}

Pulmonary rehabilitation is a cornerstone of care for people with chronic obstructive pulmonary disease (COPD), where its role and benefits have been well defined [1]. The success of pulmonary rehabilitation in improving exercise capacity, quality of life and symptoms, whilst reducing hospitalisation [2-6], has led to

Previous articles in this Series. No. 1: Gloeckl R, Marinov B, Pitta F. Practical recommendations for exercise training in patients with COPD. Eur Respir Rev 2013; 22: 178-186. No. 2: Hill K, Vogiatzis I, Burtin C. The importance of components of pulmonary rehabilitation, other than exercise training, in COPD. Eur Respir Rev 2013 22: $405-413$.

Received: Aug 212013 | Accepted after revision: Sept 242013

Conflict of interest: Disclosures can be found alongside the online version of this article at err.ersjournals.com

Provenance: Submitted article, peer reviewed.

Copyright OERS 2013. ERR articles are open access and distributed under the terms of the Creative Commons Attribution Non-Commercial Licence 3.0. 
considerable interest in whether such benefits can be extended to other patient groups [7-9]. Individuals with other chronic respiratory diseases often present with a similar constellation of signs and symptoms to those seen in COPD, including dyspnoea, fatigue, reduced exercise tolerance, avoidance of physical activity, anxiety, panic and depression [10-15]. Peripheral muscle dysfunction is also common across many chronic respiratory diseases $[13,16-18]$. To date, most pulmonary rehabilitation programmes do enrol a small number of people with chronic respiratory disease other than COPD [19]. However, differences in underlying respiratory pathophysiology, symptomatology and disease course may require modification to the standard rehabilitation format. This review considers the rationale for pulmonary rehabilitation in conditions other than COPD, the evidence underpinning its use, and the programme adaptations that may be required if the benefits of pulmonary rehabilitation are to be experienced by people with other chronic respiratory conditions. A summary of suggested programme adaptations is provided in table 1.

\section{Asthma}

People with asthma may experience recurring episodes of wheeze, dyspnoea, chest tightness and coughing [20], between which they may be relatively symptom free. As a result of these episodes, some individuals avoid physical activity and physical exercise due to the fear of triggering symptoms. Adults with asthma have been reported to have lower levels of physical fitness than their peers, as well as increased levels of psychological distress and reduced health-related quality of life (HRQoL) [10, 21, 22]. Chronic corticosteroid use may impact on peripheral muscle function [16]. Some people with asthma will develop fixed airflow obstruction in adulthood, with chronic symptoms similar to those seen in COPD [23].

Exercise training improves physical fitness in people with asthma, without deleterious effects on asthma control [24]. Importantly, more recent randomised controlled trials have also shown positive effects of exercise training on asthma symptoms and quality of life in adults with moderate-to-severe persistent asthma $[25,26]$. One of these studies was conducted in a group with a mean age of $>65$ years [26], similar to the group of older adults with asthma who may be referred to pulmonary rehabilitation. These data strengthen the rationale for inclusion of adults with persistent asthma in pulmonary rehabilitation programmes.

Exercise can be an important trigger of symptoms in some individuals, even when their asthma is otherwise well controlled. Exercise-induced bronchospasm typically occurs 5-10 min after exercise, with symptoms including breathlessness, wheeze, chest tightness or cough. For individuals with exercise-induced bronchospasm, the Global Initiative for Asthma (GINA) guidelines recommend pre-treatment with a

TABLE 1 Special considerations for pulmonary rehabilitation in people with conditions other than chronic obstructive pulmonary disease

Asthma

present, pre-medicate with a rapid-acting inhaled $\beta_{2}$-agonist prior to exercise and include a gradual warm-up

ILD

Non-CF
bronchiectasis

NSCLC
Ensure supplemental oxygen is available

Provide close supervision for individuals with severe disease and marked exercise-induced desaturation

In connective tissue-related ILD, consider modifications to avoid joint pain

A recent history of syncope on exertion is a contraindication to exercise training

Monitor PAH-specific symptoms during exercise, e.g. palpitations, chest pain, light-headedness and dizziness Consider inspiratory muscle training

Duration of pre-operative rehabilitation programme may be shorter than normal so as not to delay cancer treatment Consider alternative forms of exercise training to enhance participation in people undergoing chemotherapy
Consider breathing retraining techniques with known efficacy in asthma

Self-management training includes education, goal setting, a personalised written action plan, self-monitoring of key symptoms and a review of asthma control, treatment and skills

Consider addressing management of mood disorders, optimising activities of daily living, use of oxygen therapy, lung transplantation and advance care planning

Consider linking with support groups and education services appropriate to underlying diagnosis (e.g. rheumatoid arthritis)

Education regarding self-monitoring of $\mathrm{PAH}$ symptoms during exercise

Initiate or review airway clearance techniques

Ensure a comprehensive interdisciplinary approach Consider nutritional and psychosocial counselling, behavioural change, occupational therapy and progressive relaxation techniques

ILD: interstitial lung disease; PAH: pulmonary arterial hypertension; CF: cystic fibrosis; NSCLC: nonsmall cell lung cancer. 
rapid-acting inhaled $\beta_{2}$-agonist prior to exercise. A leukotriene modifier or cromone are effective alternatives [27]. A gradual warm-up may also minimise exercise-induced bronchospasm [28]. Cardiopulmonary exercise testing may be useful to detect exercise-induced bronchoconstriction prior to commencing an exercise programme [29].

In addition to exercise training, pulmonary rehabilitation can include other evidence-based interventions to enhance quality of life in people with asthma [30]. A systematic review and meta-analysis showed improvements in HRQoL from trials of the Buteyko breathing technique or physiotherapist-led breathing retraining (five trials, effect size 0.35 ) and yoga breathing (two trials, effect size 0.61) [31]. The follow-up periods for these studies generally did not exceed 6 months, so the longer term benefits are not yet clear. Clinicians who offer breathing exercises to people with asthma in pulmonary rehabilitation must be aware that the physiological rationale and methods for breathing retraining differ substantially from those in COPD. In asthma, breathing retraining typically aims to eliminate over-breathing by developing a slow, shallow, controlled breathing pattern. The breathing strategies used in COPD, such as pursed lip breathing and diaphragmatic breathing [32], have not been tested in people with asthma and should not be routinely offered to this patient group.

Clinicians in pulmonary rehabilitation are well placed to support and enhance self-management for people with asthma, in collaboration with the treating medical team. Whilst improving knowledge alone is not enough to improve outcomes such as hospitalisation and medication use [33], guided self-management is highly effective and considered a cornerstone of modern asthma management [27]. The GINA guidelines state that self-management for asthma requires education, joint goal setting, a personalised written action plan, self-monitoring of key symptoms, and regular review of asthma control, treatment and skills by a healthcare professional [27]. Although there is some overlap with the self-management skills taught to people with COPD in a standard pulmonary rehabilitation programme [34], there are important differences, particularly with regard to symptom monitoring and characteristics of the action plan. For instance, assessment of asthma control in a personal action plan may include frequency of rescue medication use or regular monitoring of peak expiratory flow rate. As a result, pulmonary rehabilitation clinicians should ensure that any self-management training provided meets the guideline requirements for people with asthma [27].

\section{Interstitial lung disease}

Interstitial lung diseases (ILDs) are a diverse group of chronic lung conditions that are characterised by scarring of the interstitium and a restrictive ventilatory pattern. A rapid, shallow breathing pattern is common in ILDs, which worsens on exercise and as the disease progresses [35]. Exercise-induced hypoxaemia is also common and may be profound [36]. Pulmonary hypertension is more commonly seen in ILD than in COPD [37] and further impacts on exercise tolerance [38]. Idiopathic pulmonary fibrosis (IPF), the most common of the ILDs, is associated with a poor prognosis and there are few treatment options available [39].

Despite the differences in underlying pathophysiology, many of the important disease manifestations of ILD are similar to those seen in COPD. Exertional dyspnoea may be severe and disabling [17]. Fatigue and exhaustion are also common $[40,41]$. Clinically significant depression occurs in approximately $25 \%$ of people with IPF [42]. Functional exercise tolerance is often markedly reduced, and those with the greatest impairment in exercise tolerance have the worst quality of life [43]. This constellation of symptoms and impairments is familiar to healthcare professionals in pulmonary rehabilitation.

The evidence base for pulmonary rehabilitation in ILD is small but growing. To date, two randomised controlled trials have evaluated the effects of exercise training in a group with mixed ILDs [44] and IPF only [45]. When evaluated together, these studies show short-term benefits from exercise training for functional exercise tolerance, dyspnoea and quality of life [46]. Although these benefits may be smaller in magnitude than those seen in COPD [47] and may not persist for as long [44], they are clinically significant [48]. In the context of a disease with limited treatment options and where many therapies have toxic side-effects, the potential improvements offered by pulmonary rehabilitation may be highly worthwhile for patients. Current guidelines for the management of IPF make a weak positive recommendation for pulmonary rehabilitation, indicating that it should be used in the majority of patients, but not using pulmonary rehabilitation may be a reasonable choice in a minority [39]. This recommendation acknowledges that uncertainty regarding the duration of benefit means that some patients may reasonably choose not to undertake pulmonary rehabilitation, depending on their personal circumstances.

The optimal exercise prescription for people with ILD is not yet known. Previous studies of pulmonary rehabilitation in ILD have used exercise prescriptions similar to those commonly employed in COPD [44, 45]. However, patients with ILD who have severe or rapidly progressive disease may require modifications to this 
standard approach. Where adherence to the exercise protocol is limited by distressing dyspnoea, an interval training approach may be useful [49]. Other strategies used to enhance the training effect on peripheral muscle in people with COPD and severe disease, such as neuromuscular electrical stimulation [50], may also have a role in severe ILD, although this has not yet been tested in randomised controlled trials. Supplemental oxygen should be available at all centres providing exercise training for people with ILD, given the prevalence of severe exertional oxyhaemoglobin desaturation and pulmonary hypertension [36, 38]. Close supervision during exercise is required for patients with severe disease, in whom desaturation may be difficult to control even with supplemental oxygen.

As the ILDs are a diverse group of chronic lung conditions, there may be special considerations for rehabilitation in some subgroups. Recent data suggest that in IPF, referral to pulmonary rehabilitation early in the disease course is required to attain maximum benefits, whereas those with other types of ILDs may attain benefits regardless of disease severity [51]. However, other authors have not found such an effect [52]. Given the progressive nature of IPF, some patients may be listed for lung transplantation. In this setting clinicians should consider how to provide ongoing support for exercise whilst on the waiting list. For patients with connective tissue-related ILD, joint pathology and pain are important disease manifestations [53] that should be considered when establishing an exercise programme. It is possible that a water-based exercise programme may be better suited than land-based training in some of these individuals in order to minimise joint loading, similar to that found effective in COPD [2].

Disease education has been documented as an unmet need for people with IPF [54]. Many of the standard, non-exercise components of pulmonary rehabilitation will be useful for people with ILD, such as advance care planning, optimising activities of daily living and management of mood disorders [1]. However, some elements of the COPD self-management programme will not be appropriate, such as revision of inhaler technique, breathing exercises designed for obstructive lung diseases (e.g. pursed lip breathing) and COPD action plans. In some circumstances it may be appropriate to link patients with support groups and education services appropriate to their underlying diagnosis, such as for patients with rheumatoid arthritis.

\section{Pulmonary arterial hypertension}

Pulmonary arterial hypertension (PAH) is a syndrome resulting from restricted flow through the pulmonary arterial circulation, leading to increased pulmonary vascular resistance and, ultimately, rightsided heart failure. An imbalance in the vasoconstrictor/vasodilator milieu of the pulmonary arteries and also an imbalance of proliferation and apoptosis serve as the basis for current medical therapies [55, 56]. Idiopathic PAH (IPAH) is the most commonly described variant of the disease. A high pulmonary vascular resistance and right ventricular dysfunction impair stroke volume, thereby limiting oxygen supply to the skeletal muscles. This results in lactic acidosis at low work rates and impaired functional capacity [57, 58]. Whilst PAH-specific therapies allow many patients to achieve clinical stability and prolong life, many continue to experience persistent disability, limited ability to engage in physical activities and poor HRQoL $[12,59]$. There is also increasing evidence of peripheral muscle dysfunction in people with PAH, which may contribute to ongoing reductions in exercise capacity [18].

People with PAH have often been advised to limit their participation in exercise and strenuous activities due to concerns over precipitous increases in the pulmonary pressures and the possibility of right-sided heartfailure and sudden death [59]. However, recent studies have shown clinically important benefits of exercise training in people with $\mathrm{PAH}$, without evidence of disease progression. In one of the first randomised trials on exercise training in PAH, MERELES et al. [60] reported significant improvements in exercise capacity and HRQoL following 15 weeks of daily, low-intensity endurance and strength exercises, with the first 3 weeks of the programme performed in the inpatient setting. More recently, similar benefits have been shown in trials conducted entirely in the outpatient setting [61-63]. The improvements in exercise capacity were accompanied by structural changes of the quadriceps measured by increased capillarisation and oxidative enzyme activity [61].

Whilst exercise training appears to have clinically important benefits, a recent large study has reported that it was associated with adverse events in $13 \%$ of 183 patients with a variety of causes of pulmonary hypertension, including IPAH [9]. Whilst no serious events occurred, a number of individuals experienced syncope and pre-syncope during training. This underscores the importance of appropriate symptom monitoring during exercise training. People with $\mathrm{PAH}$ may also report palpitations, chest pain, light headedness or dizziness during exercise, often with little warning. As such symptoms may not be detected by standard symptom monitoring scales used during pulmonary rehabilitation [34], clinicians should closely monitor people with PAH during exercise and should provide detailed education regarding symptoms that should be avoided. 
A combination of endurance and resistance exercise is safe and effective for people with PAH [50-54]. Early trials of exercise training for people with $\mathrm{PAH}$ used low-to-moderate intensity exercise prescriptions, such as limiting maximum heart rates during exercise to $<120$ beats per min $[60,61]$, using interval training $[60,63]$ or delaying resistance exercise until later in the programme [63]. However, a more recent randomised controlled trial has shown that treadmill training at $70-80 \%$ of heart rate reserve was well tolerated in female patients, mainly New York Heart Association (NYHA) class II and III, resulting in improved exercise tolerance and HRQoL [9]. Therefore, it may be possible for selected people with moderate PAH to train at intensities similar to other patients in pulmonary rehabilitation; however, more data are needed in this area.

To date, exercise training trials in PAH have only included participants who are stable on optimal medical therapies. A recent history of syncope on exertion is a contraindication to exercise training [60, 62]. The majority of trial participants have been in World Health Organization/NYHA classes II and III and the study findings should be primarily considered applicable to this group. Several studies have excluded participants in class IV [62-64], although a recent non-randomised study has also reported improvements in these severely affected patients [9]. It is likely that many patients in class IV will require significant reductions in the intensity of the exercise prescription, for both safety and tolerance. The benefits of exercise training do not appear to be dependent on the underlying reason for pulmonary hypertension, with benefits documented in IPAH, chronic thromboembolic pulmonary hypertension, pulmonary hypertension related to respiratory disease and pulmonary hypertension related to left heart failure [9].

In summary, there is emerging evidence that pulmonary rehabilitation and exercise training have clinically significant benefits in patients with $\mathrm{PAH}$. As pulmonary rehabilitation programmes provide close supervision, individual titration and monitoring of exercise, it is an ideal setting for people with PAH to undertake exercise training. Only patients who are stable on optimal medical therapy should be considered for an exercise programme. Because clinically important symptoms differ in PAH compared to other patients in pulmonary rehabilitation and the ideal exercise prescription is unknown, care should be taken to provide an individually targeted and carefully monitored exercise prescription.

\section{Non-cystic fibrosis bronchiectasis}

Bronchiectasis is pathologically defined as permanent dilatation of one or more bronchi, secondary to bronchial inflammation and infection. The majority of the patients suffer from idiopathic bronchiectasis [65]. Predominant symptoms include cough with sputum production, dyspnoea and fatigue, followed by reduced exercise tolerance and decreased HRQoL [66-68]. Decreased peripheral muscle strength and endurance have also been found [68]. Many patients experience recurrent exacerbations, with more frequent exacerbations predicting a poorer prognosis $[66,69]$.

International guidelines recommend the inclusion of people with bronchiectasis in pulmonary rehabilitation to improve physical capacity and HRQoL [34]. However, there are only two randomised controlled trials that have investigated the effect of pulmonary rehabilitation in patients with non-cystic fibrosis bronchiectasis. Both these trials tested interventions that were different to the traditional pulmonary rehabilitation model. In the first reported randomised controlled trial of pulmonary rehabilitation for bronchiectasis, 32 individuals were randomised to receive an 8-week pulmonary rehabilitation programme consisting of endurance exercise training, with or without inspiratory muscle training, or no exercise [70]. There were positive effects on exercise capacity in both exercise groups, but intriguingly, only the group that performed inspiratory muscle training improved their HRQoL. The inspiratory muscle training group also maintained the improved exercise capacity at a 3-month follow-up, which the exercise-only group did not [70]. In a randomised controlled pilot study on 30 patients, the effect of 8 weeks of pulmonary rehabilitation and airway clearance techniques (using oscillatory positive expiratory pressure) was compared to airway clearance techniques alone. They found that addition of pulmonary rehabilitation, including two supervised and one home-based exercise session per week consisting of endurance and strength training, improved exercise capacity and HRQoL more than airway clearance alone [71]. To date, there have been no trials that have reported the effects of pulmonary rehabilitation on exacerbations or hospitalisations in bronchiectasis.

Whilst these results suggest a role for exercise training in people with bronchiectasis, the other components of pulmonary rehabilitation remain to be defined. Although inspiratory muscle training is not a routine component of pulmonary rehabilitation for COPD [1], it may be more useful in bronchiectasis, although the rationale for its use needs further clarification. Airway clearance techniques alone have positive effects on sputum expectoration, some measures of lung function and HRQoL in people with bronchiectasis [72]. A pulmonary rehabilitation programme may provide an ideal opportunity to initiate or optimise airway clearance for people with bronchiectasis, with regular monitoring and technique review. 
The available evidence indicates that exercise training is useful in patients with bronchiectasis to improve exercise capacity and HRQoL. Further studies are needed to find out how the traditional pulmonary rehabilitation programmes should be optimised for people with bronchiectasis and whether pulmonary rehabilitation can impact on longer term outcomes.

\section{Nonsmall cell lung cancer}

Lung cancer is one of the most common cancers worldwide, and is mostly caused by tobacco smoking [73]. It is generally divided into nonsmall cell lung cancer (NSCLC) and small cell lung cancer, with NSCLC representing $85-90 \%$ of all cases [74]. Treatment of lung cancer (i.e. surgery, radiotherapy and/or chemotherapy) depends on disease stage, but also on the presence of comorbidities, functional performance, quality of life and peak aerobic capacity [75-77]. Despite many aggressive treatment strategies, it remains the most common cause of cancer-related death [78].

Cancer-related symptoms of dyspnoea and fatigue probably reduce daily physical activity levels in people with NSCLC [79]. Moreover, people with NSCLC suffer from physical deconditioning, including a poor peak aerobic capacity [80], symptoms of depression [81] and a poor quality of life compared with healthy subjects [82]. Pre-operative peak exercise treadmill tests were stopped because of leg discomfort in $70 \%$ of the people with NSCLC [83], suggesting that extrapulmonary features, like skeletal muscle dysfunction, may contribute to the poor exercise performance. This hypothesis is strengthened by the fact that pre-operative peak aerobic capacity is not related to spirometric impairments [84], and people with NSCLC have lower quadriceps muscle strength compared to healthy subjects [85].

Patients' daily symptoms of dyspnoea, physical activity levels, peak exercise performance, stair climbing performance and quality of life worsen directly following surgery, and remain impaired for 6 months or longer after surgery [86-91]. The variance in decline in peak aerobic capacity following lobar pulmonary resection can only be explained in part by the change in lung function [92]. Indeed, exercise $>6$ months after lobectomy is still limited due to leg discomfort in a majority of patients [83]. These findings suggest that lower limb muscle deconditioning is still the underlying cause of exercise intolerance following lung resection. Physical activity levels do not spontaneously recover, remaining lower than pre-operative levels up to 3.5 years after surgical lung resection for NSCLC $[90,91]$. Therefore, there is a strong rationale to consider people with NSCLC for referral to pre-operative and post-operative pulmonary rehabilitation programmes.

Data on pre-operative pulmonary rehabilitation in people with NSCLC are sparse. This may partially explain why only a minority of the centres performing thoracic surgery offer pre-operative pulmonary rehabilitation or vice versa [93]. Implementing pulmonary rehabilitation in the period between diagnosing NSCLC and its treatment may be challenging, as patients and healthcare professionals are reluctant to delay cancer treatment [94]. MORANO et al. [95] found that 4 weeks of pulmonary rehabilitation (including upper limb strength training with free weights, aerobic training in a treadmill, inspiratory muscle training and education) had positive effects on pre-operative functional exercise capacity compared to chest physical therapy in patients awaiting lung cancer resection. Moreover, a lower incidence of post-operative respiratory morbidity and a shorter length of post-operative stay were observed following pre-operative pulmonary rehabilitation [95]. Others have also reported a shorter length of hospital stay following 10 sessions of pre-operative pulmonary rehabilitation (including exercise prescription based on self-efficacy, inspiratory muscle training and the practice of slow breathing) compared to usual care [94]. So, preliminary evidence suggests that pre-operative pulmonary rehabilitation is feasible and beneficial for people with NSCLC, but large, randomised controlled trials are currently lacking.

Grade A evidence on the efficacy of post-operative exercise-based pulmonary rehabilitation in people with NSCLC is also limited [96]. Nevertheless, a subgroup of people with lung cancer may benefit from postoperative pulmonary rehabilitation. To date, physiotherapy services of hospitals mainly focus on reducing or preventing post-operative pulmonary complications in people who undergo surgical resection for lung cancer [97]. Despite numerous reports on the positive effects of post-operative exercise training on cancerrelated symptoms, lower limb muscle function, exercise performance and quality of life in people with NSCLC [98-102], referral for post-operative pulmonary rehabilitation is $<25 \%$ [97]. This may be due to the fact that large, randomised controlled trials and, in turn, robust evidence of the efficacy of pulmonary rehabilitation in people who underwent lung cancer resection are currently lacking [96].

Whether and to what extent chemotherapy may influence the effects of pulmonary rehabilitation remains unclear. Preliminary data suggest that significant improvements in quality of life, exercise performance and fatigue particularly occur among people not receiving chemotherapy [80]. However, this should be confirmed in larger studies. Alternative forms of exercise training may be required to enhance participation in people undergoing chemotherapy. An uncontrolled study showed that people initiating and completing post-operative chemotherapy and/or radiation therapy showed high adherence rates (88\%) using the 
Nintendo Wii Fit Plus (Nintendo Co. Ltd, Kyoto, Japan), accompanied by improved cancer-related fatigue scores [103].

People surgically treated for NSCLC may have a prior cancer other than lung cancer, heart disease, osteoporosis, COPD, asthma and/or osteoarthritis [90, 99, 100], which may complicate the process and affect the outcomes of pulmonary rehabilitation. Therefore, post-operative pulmonary rehabilitation should start with a comprehensive assessment in a specialised rehabilitation clinic [104], including screening of comorbidities based on validated objective measurements [105], to establish an individualised pulmonary rehabilitation programme.

Most post-operative exercise training programmes are derived from existing COPD training programmes, or are integrated in a group of people with COPD $[99,106]$. Supervised programmes have consisted of cycle ergometry, treadmill walking, weight training, gymnastics or a combination thereof [98, 99]. Training loads were comparable to those of people with COPD, and progressed over time, on the basis of symptom scores for dyspnoea and/or fatigue to maintain the same relative perceived training load during the intervention period [99]. For people who are not able to adhere to these exercise training modalities due to dyspnoea and/or fatigue, t'ai chi [107] or neuromuscular electrostimulation may be a reasonable alternatives [108].

Based on the clinical complexity of people with NSCLC, a comprehensive interdisciplinary approach seems imperative. In addition to exercise training, nutritional and psychosocial counselling, behavioural change, occupational therapy and progressive relaxation techniques should be considered [1, 109]. Indeed, postoperative breathing exercises, including inspiratory muscle training, simple relaxation techniques, activity pacing or psychosocial support under the guidance of physicians and nurse seems to improve lung function and quality of life [110]. CESARIO et al. [98] also provided educational sessions focussing on pulmonary pathophysiology, the pharmacology of medications, dietary counselling, relaxation and stress management techniques, energy conservation principles and breathing retraining. Although this approach seems very reasonable, the efficacy of post-operative education remains to be determined.

\section{Conclusion}

The current English-language peer-reviewed literature suggests that people with chronic respiratory diseases other than COPD may also benefit from a comprehensive, interdisciplinary pulmonary rehabilitation programme. As well as the documented benefits of pulmonary rehabilitation in asthma, ILD, PAH, noncystic fibrosis bronchiectasis and lung cancer that are outlined in this review, it may also be useful in other chronic conditions such as cystic fibrosis, neuromuscular disease and individuals following lung transplantation [1]. Existing COPD programmes can easily be adapted to specific needs of these patients, in particular the non-exercising parts. Nevertheless, chest physicians need to become aware of the positive effects of this non-pharmacological intervention to increase referral rates and, in turn, improve the integrated care of people with chronic respiratory diseases.

\section{References}

1 Spruit MA, Singh SJ, Garvey C, et al. An Official American Thoracic Society/European Respiratory Society Statement: key concepts and advances in pulmonary rehabilitation - an Executive Summary. Am J Respir Crit Care Med 2013 [in press].

2 McNamara RJ, McKeough ZJ, McKenzie DK, et al. Water-based exercise in COPD with physical comorbidities: a randomised controlled trial. Eur Respir J 2013; 41: 1284-1291.

3 Leung RW, McKeough ZJ, Peters MJ, et al. Short-form Sun-style t'ai chi as an exercise training modality in people with COPD. Eur Respir J 2013; 41: 1051-1057.

4 Gouzi F, Prefaut C, Abdellaoui A, et al. Blunted muscle angiogenic training-response in COPD patients versus sedentary controls. Eur Respir J 2013; 41: 806-814.

5 Bronstad E, Rognmo O, Tjonna AE, et al. High-intensity knee extensor training restores skeletal muscle function in COPD patients. Eur Respir J 2012; 40: 1130-1136.

6 Burtin C, Saey D, Saglam M, et al. Effectiveness of exercise training in patients with COPD: the role of muscle fatigue. Eur Respir J 2012; 40: 338-344.

7 Huppmann P, Sczepanski B, Boensch M, et al. Effects of inpatient pulmonary rehabilitation in patients with interstitial lung disease. Eur Respir J 2013; 42: 444-453.

8 Rubin LJ. Exercise training for pulmonary hypertension: another prescription to write? Eur Respir J 2012; 40: 7-8.

9 Grunig E, Lichtblau M, Ehlken N, et al. Safety and efficacy of exercise training in various forms of pulmonary hypertension. Eur Respir J 2012; 40: 84-92.

10 Wertz DA, Pollack M, Rodgers K, et al. Impact of asthma control on sleep, attendance at work, normal activities, and disease burden. Ann Allergy Asthma Immunol 2010; 105: 118-123.

11 Ryerson CJ, Arean PA, Berkeley J, et al. Depression is a common and chronic comorbidity in patients with interstitial lung disease. Respirology 2012; 17: 525-532.

12 Taichman DB, Shin J, Hud L, et al. Health-related quality of life in patients with pulmonary arterial hypertension. Respir Res 2005; 6: 92.

13 Spruit MA, Thomeer MJ, Gosselink R, et al. Skeletal muscle weakness in patients with sarcoidosis and its relationship with exercise intolerance and reduced health status. Thorax 2005; 60: 32-38. 


$$
\text { 101: 2502-2510. }
$$

Spruit MA, Thomeer MJ, Gosselink R, et al. Hypogonadism in male outpatients with sarcoidosis. Respir Med 2007;

15 Spruit MA, Janssen DJ, Franssen FM, et al. Rehabilitation and palliative care in lung fibrosis. Respirology 2009; 14: 781-787.

16 Decramer M, Lacquet LM, Fagard R, et al. Corticosteroids contribute to muscle weakness in chronic airflow obstruction. Am J Respir Crit Care Med 1994; 150: 11-16.

17 Nishiyama O, Taniguchi H, Kondoh Y, et al. Quadriceps weakness is related to exercise capacity in idiopathic pulmonary fibrosis. Chest 2005; 127: 2028-2033.

18 Mainguy V, Maltais F, Saey D, et al. Peripheral muscle dysfunction in idiopathic pulmonary arterial hypertension. Thorax 2010; 65: 113-117.

19 Yohannes AM, Connolly MJ. Pulmonary rehabilitation programmes in the UK: a national representative survey. Clin Rehabil 2004; 18: 444-449.

20 Global Initiative for Asthma (GINA). Global Strategy for Asthma Management and Prevention. Bethesda, National Heart, Lung, and Blood Institute of Health, 2006.

21 Clark CJ, Cochrane LM. Assessment of work performance in asthma for determination of cardiorespiratory fitness and training capacity. Thorax 1988; 43: 745-749.

22 Adams RJ, Wilson DH, Taylor AW, et al. Psychological factors and asthma quality of life: a population based study. Thorax 2004; 59: 930-935.

23 Oga T, Tsukino M, Hajiro T, et al. Multidimensional analyses of long-term clinical courses of asthma and chronic obstructive pulmonary disease. Allergol Int 2010; 59: 257-265.

24 Chandratilleke MG, Carson KV, Picot J, et al. Physical training for asthma. Cochrane Database Syst Rev 2012; 5: CD001116.

25 Mendes FA, Goncalves RC, Nunes MP, et al. Effects of aerobic training on psychosocial morbidity and symptoms in patients with asthma: a randomized clinical trial. Chest 2010; 138: 331-337.

26 Turner S, Eastwood P, Cook A, et al. Improvements in symptoms and quality of life following exercise training in older adults with moderate/severe persistent asthma. Respiration 2011; 81: 302-310.

27 Global Strategy for Asthma Management and Prevention. Global Initiative for Asthma (GINA). 2002. www.ginasthma.org/local/uploads/files/GINA_Report_March13.pdf Date last updated: 2012. Date last accessed: August 1, 2013.

28 Reiff DB, Choudry NB, Pride NB, et al. The effect of prolonged submaximal warm-up exercise on exercise-induced asthma. Am Rev Respir Dis 1989; 139: 479-484.

29 Crapo RO, Casaburi R, Coates AL, et al. Guidelines for methacholine and exercise challenge testing - 1999. Am J Respir Crit Care Med 2000; 161: 309-329.

30 Hill K, Vogiatzis I, Burtin C. The importance of components of pulmonary rehabilitation, other than exercise training, in COPD. Eur Respir Rev 2013; 22: 405-413.

31 Burgess J, Ekanayake B, Lowe A, et al. Systematic review of the effectiveness of breathing retraining in asthma management. Expert Rev Respir Med 2011; 5: 789-807.

32 Holland AE, Hill CJ, Jones AY, et al. Breathing exercises for chronic obstructive pulmonary disease. Cochrane Database Syst Rev 2012; 10: CD008250.

33 Gibson PG, Powell H, Coughlan J, et al. Limited (information only) patient education programs for adults with asthma. Cochrane Database Syst Rev, 2002: CD001005.

34 Nici L, Donner C, Wouters E, et al. American Thoracic Society/European Respiratory Society statement on pulmonary rehabilitation. Am J Respir Crit Care Med 2006; 173: 1390-1413.

35 Javaheri S, Sicilian L. Lung function, breathing pattern, and gas exchange in interstitial lung disease. Thorax 1992; 47: 93-97.

36 Lama VN, Flaherty KR, Toews GB, et al. Prognostic value of desaturation during a 6-minute walk test in idiopathic interstitial pneumonia. Am J Respir Crit Care Med 2003; 168: 1084-1090.

37 Shorr AF, Wainright JL, Cors CS, et al. Pulmonary hypertension in patients with pulmonary fibrosis awaiting lung transplant. Eur Respir J 2007; 30: 715-721.

38 Glaser S, Noga O, Koch B, et al. Impact of pulmonary hypertension on gas exchange and exercise capacity in patients with pulmonary fibrosis. Respir Med 2009; 103: 317-324.

39 Raghu G, Collard HR, Egan JJ, et al. An Official ATS/ERS/JRS/ALAT Statement. Idiopathic pulmonary fibrosis: evidence-based guidelines for diagnosis and management. Am J Respir Crit Care Med 2011; 183: 788-824.

40 Swigris JJ, Fairclough DL, Morrison M, et al. Beneficial effects of pulmonary rehabilitation in idiopathic pulmonary fibrosis. Respir Care 2011; 56: 783-789.

41 Swigris JJ, Gould MK, Wilson SR. Health-related quality of life among patients with idiopathic pulmonary fibrosis. Chest 2005; 127: 284-294.

42 Ryerson CJ, Berkeley J, Carrieri-Kohlman VL, et al. Depression and functional status are strongly associated with dyspnea in interstitial lung disease. Chest 2011; 139: 609-616.

43 Chang JA, Curtis JR, Patrick DL, et al. Assessment of health-related quality of life in patients with interstitial lung disease. Chest 1999; 116: 1175-1182.

44 Holland AE, Hill CJ, Conron M, et al. Short term improvement in exercise capacity and symptoms following exercise training in interstitial lung disease. Thorax 2008; 63: 549-554.

45 Nishiyama O, Kondoh Y, Kimura T, et al. Effects of pulmonary rehabilitation in patients with idiopathic pulmonary fibrosis. Respirology 2008; 13: 394-399.

46 Holland A, Hill C. Physical training for interstitial lung disease. Cochrane Database Syst Rev 2008; 4: CD006322.

47 Lacasse Y, Goldstein R, Lasserson TJ, et al. Pulmonary rehabilitation for chronic obstructive pulmonary disease. Cochrane Database Syst Rev 2006; 4: CD003793.

48 Holland AE, Hill CJ, Conron M, et al. Small changes in six-minute walk distance are important in diffuse parenchymal lung disease. Respir Med 2009; 103: 1430-1435.

49 Gloeckl R, Marinov B, Pitta F. Practical recommendations for exercise training in patients with COPD. Eur Respir Rev 2013; 22: 178-186. 
50 Sillen MJ, Speksnijder CM, Eterman RM, et al. Effects of neuromuscular electrical stimulation of muscles of ambulation in patients with chronic heart failure or COPD: a systematic review of the English-language literature. Chest 2009; 136: 44-61.

51 Holland AE, Hill CJ, Glaspole I, et al. Predictors of benefit following pulmonary rehabilitation for interstitial lung disease. Respir Med 2012; 106: 429-435.

52 Ferreira A, Garvey C, Connors GL, et al. Pulmonary rehabilitation in interstitial lung disease: benefits and predictors of response. Chest 2009; 135: 442-447.

53 Garin MC, Highland KB, Silver RM, et al. Limitations to the 6-minute walk test in interstitial lung disease and pulmonary hypertension in scleroderma. J Rheumatol 2009; 36: 330-336.

54 Schoenheit G, Becattelli I, Cohen AH. Living with idiopathic pulmonary fibrosis: an in-depth qualitative survey of European patients. Chron Respir Dise 2011; 8: 225-231.

55 McLaughlin VV, Archer SL, Badesch DB, et al. ACCF/AHA 2009 expert consensus document on pulmonary hypertension: a report of the American College of Cardiology Foundation Task Force on Expert Consensus Documents and the American Heart Association: developed in collaboration with the American College of Chest Physicians, American Thoracic Society, Inc., and the Pulmonary Hypertension Association. Circulation 2009; 119: 2250-2294.

56 Seferian A, Simonneau G. Therapies for pulmonary arterial hypertension: where are we today, where do we go tomorrow? Eur Respir Rev 2013; 22: 217-226.

57 Deboeck G, Niset G, Lamotte M, et al. Exercise testing in pulmonary arterial hypertension and in chronic heart failure. Eur Respir J 2004; 23: 747-751.

58 Yasunobu Y, Oudiz RJ, Sun XG, et al. End-tidal $\mathrm{PCO}_{2}$ abnormality and exercise limitation in patients with primary pulmonary hypertension. Chest 2005; 127: 1637-1646.

59 Desai SA, Channick RN. Exercise in patients with pulmonary arterial hypertension. J Cardiopulm Rehabil Prev 2008; 28: 12-16.

60 Mereles D, Ehlken N, Kreuscher S, et al. Exercise and respiratory training improve exercise capacity and quality of life in patients with severe chronic pulmonary hypertension. Circulation 2006; 114: 1482-1489.

61 de Man FS, Handoko ML, Groepenhoff $\mathrm{H}$, et al. Effects of exercise training in patients with idiopathic pulmonary arterial hypertension. Eur Respir J 2009; 34: 669-675.

62 Mainguy V, Maltais F, Saey D, et al. Effects of a rehabilitation program on skeletal muscle function in idiopathic pulmonary arterial hypertension. J Cardiopulm Rehabil Prev 2010; 30: 319-323.

63 Fox BD, Kassirer M, Weiss I, et al. Ambulatory rehabilitation improves exercise capacity in patients with pulmonary hypertension. J Card Fail 2011; 17: 196-200.

64 Chan L, Chin LM, Kennedy M, et al. Benefits of intensive treadmill exercise training on cardiorespiratory function and quality of life in patients with pulmonary hypertension. Chest 2013; 143: 333-343.

65 Tsang KW, Bilton D. Clinical challenges in managing bronchiectasis. Respirology 2009; 14: 637-650.

66 Martinez-Garcia MA, Perpina-Tordera M, Roman-Sanchez P, et al. Quality-of-life determinants in patients with clinically stable bronchiectasis. Chest 2005; 128: 739-745.

67 Koulouris NG, Retsou S, Kosmas E, et al. Tidal expiratory flow limitation, dyspnoea and exercise capacity in patients with bilateral bronchiectasis. Eur Respir J 2003; 21: 743-748.

68 Ozalp O, Inal-Ince D, Calik E, et al. Extrapulmonary features of bronchiectasis: muscle function, exercise capacity, fatigue, and health status. Multidiscip Respir Med 2012; 7: 3.

69 King PT, Holdsworth SR, Freezer NJ, et al. Outcome in adult bronchiectasis. COPD 2005; 2: 27-34.

70 Newall C, Stockley RA, Hill SL. Exercise training and inspiratory muscle training in patients with bronchiectasis. Thorax 2005; 60: 943-948.

71 Mandal P, Sidhu MK, Kope L, et al. A pilot study of pulmonary rehabilitation and chest physiotherapy versus chest physiotherapy alone in bronchiectasis. Respir Med 2012; 106: 1647-1654.

72 Lee AL, Burge A, Holland AE. Airway clearance techniques for bronchiectasis. Cochrane Database Syst Rev 2013; 5 : CD008351.

73 Jemal A, Thun MJ, Ries LA, et al. Annual report to the nation on the status of cancer, 1975-2005, featuring trends in lung cancer, tobacco use, and tobacco control. J Natl Cancer Inst 2008; 100: 1672-1694.

74 Govindan R, Page N, Morgensztern D, et al. Changing epidemiology of small-cell lung cancer in the United States over the last 30 years: analysis of the surveillance, epidemiologic, and end results database. J Clin Oncol 2006; 24: $4539-4544$.

75 Firat S, Bousamra M, Gore E, et al. Comorbidity and KPS are independent prognostic factors in stage I non-smallcell lung cancer. Int J Radiat Oncol Biol Phys 2002; 52: 1047-1057.

76 Pompili C, Salati M, Refai M, et al. Preoperative quality of life predicts survival following pulmonary resection in stage I non-small-cell lung cancer. Eur J Cardiothorac Surg 2013; 43: 905-910.

77 Brunelli A, Pompili C, Berardi R, et al. Performance at preoperative stair-climbing test is associated with prognosis after pulmonary resection in stage I non-small cell lung cancer. Ann Thorac Surg 2012; 93: 1796-1800.

78 Jemal A, Siegel R, Ward E, et al. Cancer statistics, 2009. CA Cancer J Clin 2009; 59: 225-249.

79 Wilcock A, Maddocks M, Lewis M, et al. Symptoms limiting activity in cancer patients with breathlessness on exertion: ask about muscle fatigue. Thorax 2008; 63: 91-92.

80 Jones LW, Eves ND, Mackey JR, et al. Safety and feasibility of cardiopulmonary exercise testing in patients with advanced cancer. Lung Cancer 2007; 55: 225-232.

81 Castelli L, Binaschi L, Caldera P, et al. Depression in lung cancer patients: is the HADS an effective screening tool? Support Care Cancer 2009; 17: 1129-1132.

82 Brunelli A, Socci L, Refai M, et al. Quality of life before and after major lung resection for lung cancer: a prospective follow-up analysis. Ann Thorac Surg 2007; 84: 410-416.

83 Nezu K, Kushibe K, Tojo T, et al. Recovery and limitation of exercise capacity after lung resection for lung cancer. Chest 1998; 113: 1511-1516.

84 Morice RC, Peters EJ, Ryan MB, et al. Exercise testing in the evaluation of patients at high risk for complications from lung resection. Chest 1992; 101: 356-361. 
85 Op den Kamp CM, Langen RC, Snepvangers FJ, et al. Nuclear transcription factor kappaB activation and protein turnover adaptations in skeletal muscle of patients with progressive stages of lung cancer cachexia. Am J Clin Nutr 2013; 98: 738-748.

86 Nagamatsu Y, Maeshiro K, Kimura NY, et al. Long-term recovery of exercise capacity and pulmonary function after lobectomy. J Thorac Cardiovasc Surg 2007; 134: 1273-1278.

87 Handy JR Jr, Asaph JW, Skokan L, et al. What happens to patients undergoing lung cancer surgery? Outcomes and quality of life before and after surgery. Chest 2002; 122: 21-30.

88 Schulte T, Schniewind B, Dohrmann P, et al. The extent of lung parenchyma resection significantly impacts longterm quality of life in patients with non-small cell lung cancer. Chest 2009; 135: 322-329.

89 Brunelli A, Monteverde M, Salati M, et al. Stair-climbing test to evaluate maximum aerobic capacity early after lung resection. Ann Thorac Surg 2001; 72: 1705-1710.

90 Coups EJ, Park BJ, Feinstein MB, et al. Physical activity among lung cancer survivors: changes across the cancer trajectory and associations with quality of life. Cancer Epidemiol Biomarkers Prev 2009; 18: 664-672.

91 Novoa N, Varela G, Jimenez MF, et al. Influence of major pulmonary resection on postoperative daily ambulatory activity of the patients. Interact Cardiovasc Thorac Surg 2009; 9: 934-938.

92 Bobbio A, Chetta A, Carbognani P, et al. Changes in pulmonary function test and cardio-pulmonary exercise capacity in COPD patients after lobar pulmonary resection. Eur J Cardiothorac Surg 2005; 28: 754-758.

93 Agostini P, Reeve J, Dromard S, et al. A survey of physiotherapeutic provision for patients undergoing thoracic surgery in the UK. Physiotherapy 2013; 99: 56-62.

94 Benzo R, Wigle D, Novotny P, et al. Preoperative pulmonary rehabilitation before lung cancer resection: results from two randomized studies. Lung Cancer 2011; 74: 441-445.

95 Morano MT, Araujo AS, Nascimento FB, et al. Preoperative pulmonary rehabilitation versus chest physical therapy in patients undergoing lung cancer resection: a pilot randomized controlled trial. Arch Phys Med Rehabil 2013; 94: 53-58.

96 Cavalheri V, Tahirah F, Nonoyama M, et al. Exercise training undertaken by people within 12 months of lung resection for non-small cell lung cancer. Cochrane Database Syst Rev 2013; 7: CD009955.

97 Cavalheri V, Jenkins S, Hill K. Physiotherapy practice patterns for patients undergoing surgery for lung cancer: a survey of hospitals in Australia and New Zealand. Intern Med J 2013; 43: 394-401.

98 Cesario A, Ferri L, Galetta D, et al. Post-operative respiratory rehabilitation after lung resection for non-small cell lung cancer. Lung Cancer 2007; 57: 175-180.

99 Spruit MA, Janssen PP, Willemsen SC, et al. Exercise capacity before and after an 8-week multidisciplinary inpatient rehabilitation program in lung cancer patients: a pilot study. Lung Cancer 2006; 52: 257-260.

100 Jones LW, Eves ND, Peterson BL, et al. Safety and feasibility of aerobic training on cardiopulmonary function and quality of life in postsurgical nonsmall cell lung cancer patients: a pilot study. Cancer 2008; 113: 3430-3439.

101 Granger CL, Chao C, McDonald CF, et al. Safety and feasibility of an exercise intervention for patients following lung resection: a pilot randomized controlled trial. Integr Cancer Ther 2013; 12: 213-224.

102 Peddle-McIntyre CJ, Bell G, Fenton D, et al. Feasibility and preliminary efficacy of progressive resistance exercise training in lung cancer survivors. Lung Cancer 2012; 75: 126-132.

103 Hoffman AJ, Brintnall RA, Brown JK, et al. Virtual reality bringing a new reality to postthoracotomy lung cancer patients via a home-based exercise intervention targeting fatigue while undergoing adjuvant treatment. Cancer Nurs 2013 [in press DOI: 10.1097/NCC.0b013e318278d52f].

104 Spruit MA, Vanderhoven-Augustin I, Janssen PP, et al. Integration of pulmonary rehabilitation in COPD. Lancet 2008; 371: 12-13.

105 Vanfleteren LE, Spruit MA, Groenen M, et al. Clusters of comorbidities based on validated objective measurements and systemic inflammation in patients with chronic obstructive pulmonary disease. Am J Respir Crit Care Med 2013; 187: 728-735.

106 Jones LW, Eves ND, Kraus WE, et al. The lung cancer exercise training study: a randomized trial of aerobic training, resistance training, or both in postsurgical lung cancer patients: rationale and design. BMC Cancer 2010; 10: 155.

107 Wang R, Liu J, Chen P, et al. Regular tai chi exercise decreases the percentage of type 2 cytokine-producing cells in postsurgical non-small cell lung cancer survivors. Cancer Nurs 2013; 36: E27-E34.

108 Maddocks M, Lewis M, Chauhan A, et al. Randomized controlled pilot study of neuromuscular electrical stimulation of the quadriceps in patients with non-small cell lung cancer. J Pain Symptom Manage 2009; 38: 950-956.

109 Dimeo FC, Thomas F, Raabe-Menssen C, et al. Effect of aerobic exercise and relaxation training on fatigue and physical performance of cancer patients after surgery. A randomised controlled trial. Support Care Cancer 2004; 12: 774-779.

110 Liu W, Pan YL, Gao CX, et al. Breathing exercises improve post-operative pulmonary function and quality of life in patients with lung cancer: A meta-analysis. Exp Ther Med 2013; 5: 1194-1200. 